\title{
Transcript analyses of stromal cell derived factors (SDFs): SDF-2, SDF-4 and SDF-5 reveal a different pattern of expression and prognostic association in human breast cancer
}

\author{
HUA KANG ${ }^{1,3}$, ASTRID ESCUDERO-ESPARZA ${ }^{1}$, ANTHONY DOUGLAS-JONES ${ }^{2}$, \\ ROBERT E. MANSEL ${ }^{1}$ and WEN G. JIANG ${ }^{1}$ \\ ${ }^{1}$ Metastasis and Angiogenesis Research Group and ${ }^{2}$ Department of Pathology, Cardiff University School of Medicine, \\ Cardiff, UK; ${ }^{3}$ Department of General Surgery, Xuanwu Hospital, Capital Medical University, Beijing 100053, P.R. China
}

Received January 28, 2009; Accepted April 9, 2009

DOI: 10.3892/ijo_00000330

\begin{abstract}
Stromal derived factors, SDFs, are a loosely defined group of molecules that may be generated by stromal cells. Two of the stromal derived factors, SDF-1 and SDF-4 belong to the chemokine family. Other SDFs, such as SDF-2 and SDF-5 are not well defined and their biological functions are less known. Although SDF-1 and its receptor have been strongly indicated in the progression of various cancers including breast cancer, little is known with regard to the role of other SDFs in malignant conditions including breast cancer. In the present study, we analysed the pattern of expression of SDF-2, SDF2-like-1, SDF-4 and SDF-5 in breast cancer tissues and cells, at transcript and protein levels. It was found that SDF-2, SDF2-L1, SDF-4, and SDF-5 were ubiquitously expressed in various cancer cell lines. However, in clear contrast to SDF-1 whose over-expression has been shown to be linked to a poor clinical outcome, the present study provides evidence that the opposite appear to be true for SDF-2/SDF2-L1, SDF-4 and SDF-5. Significantly low levels of SDF-2 and SDF-4 were seen in patients with poor clinical outcome (with metastatic disease and death as a result of breast cancer, $\mathrm{p}<0.05$, and $\mathrm{p}<0.01$ respectively), when compared with patients who remained disease-free. SDF2-L1 and SDF-5 showed a similar trend. SDF-2 and SDF-L1 were also independent prognostic indicators $(\mathrm{p}=0.047$ and $\mathrm{p}=0.012$, respectively). It is concluded that SDF-2, SDF-4 and SDF-5 are expressed in mammary tissues and cells and that a reduced level of SDF-2, SDF2-L1 and SDF-4 are associated with a poor clinical outcome. These SDFs thus
\end{abstract}

Correspondence to: Dr Wen G. Jiang, Metastasis and Angiogenesis Research Group, Cardiff University School of Medicine, Cardiff CF14 4XN, UK

E-mail: jiangw@cf.ac.uk

Key words: stromal cell derived factor, SDF-2, SDF2-like, SDF-4, SDF-5, breast cancer, prognosis, survival have prognostic value and warrant further investigation in their biological functions and clinical value.

\section{Introduction}

Stromal cell derived factors refer to a group of proteins that are derived from stromal cells, including fibroblasts. The best described of such factors is SDF-1/CXCL12 (CXC motif, ligand 12), which is a known chemotactic cytokine. SDF-1 is also a member of CXC subfamily of chemokines, which are expressed in several tissues and organs, including skin, lymph nodes, lung, liver, and bone marrow, and mainly produced by stromal cells such as fibroblasts and bone marrow endothelial cells (1-3). SDF-1, via its receptor CXCR4, plays an important role in physiological and pathological conditions including cancer (4-7). We have recently demonstrated that SDF-1 was over-expressed in human breast cancer and the level of SDF-1 was significantly correlated with the metastasis and overall survival in human breast cancer (8-10).

However, other stromal derived factors, are less well defined. In the last decade, SDF-2, SDF-3, SDF-4, and SDF-5 have been identified. Except SDF-3 which has only been described in murine samples, SDF-2 (11), SDF-4 (12) and SDF-5 (13) have been reported in humans. In addition, a variant of SDF-2 has also been reported, and so named SDF2-like-1 protein (14). SDF-4, also known as Cab45, is a $\mathrm{Ca}^{2+}$-binding protein localised in the Golgi lumen $(12,15-17)$.

SDF-2 was initially identified from mouse stromal cell line ST2 (11), which is a 211-amino acid protein that includes a 30-amino acid hydrophobic signal peptide. Because the protein lacks a hydrophobic region in addition to that at the $\mathrm{N}$ terminus. It has been suggested that the protein is likely to be a secretory and not a membrane protein. A human homologue of murine SDF-2 was also identified from a glioblastoma cell line, a protein that is $92.4 \%$ identical to that of the mouse (11). SDF-4, also known as Cab45, is a $45-\mathrm{kDa}$ protein identified from mouse 3T3-L1 adipocytes (15). It is a $\mathrm{Ca}^{2+}$-binding protein localised in the Golgi lumen (15-17). SDF4/Cab45 is ubiquitously expressed and binds $\mathrm{Ca}^{2+}$ due to the presence of six EF-hand motifs. Within the superfamily of calcium-binding proteins, 
it belongs to a recently identified group of proteins consisting of reticulocalbin.

Little is known about these new SDFs in cancer. In colorectal cancer, SDF-2 was reported to be under-expressed in cancer and that the reduction of SDF-2 may be linked to a poor survival (18). SDF-4 has been shown to be an overexpressed protein and a potential new biomarker in pancreatic cancer cell lines (17). There has been no study on the expression of SDF-2, SDF-4, SDF-5 in breast cancer. In the present study, we evaluated the expression of SDF-2/-4/-5 and SDF2-like molecules in a panel of cancer cell lines and a cohort of breast tumours, whose SDF-1 expression pattern was previously reported (8). A further aim of the study was to deduce a possible correlation between SDFs and clinical outcome and compare the pattern of expression with SDF-1.

\section{Materials and methods}

Materials. Monocloncal anti-human SDF-2 (SC100660), goat anti-human SDF-4 (SC-47373) and goat anti-human SDF-1 (SC-6193) antibodies and a universal staining kit were from Santa Cruz Biotechnology Ltd. (Santa Cruz, CA, USA), and Vector Laboratories (Nottingham, UK), respectively. Human breast cancer cell lines, MDA-MB-231, MDA-MB-436, MCF-7, ZR-75-1, BT474, BT482, BT549, human fibroblast cell line MRC5, were obtain from ATCC (MD, USA) and ECACC (Salisbury, UK) respectively. Human endothelial cell line HECV was from from Interlab Cell line Collection (ICLC, Naples, Italy). RNA extraction kit and the first strand RT synthesis kits were obtained from AbGene Ltd. (Surrey, UK). PCR primers were designed using Beacon Designer (Palo Alto, CA, USA) and synthesised by Invitrogen Ltd. (Pasley, Scotland, UK). Primer sequences are given in Table I. Molecular biology grade agarose and DNA ladder were from Invitrogen. Master mix for routine PCR and quantitative PCR was from AbGene.

Mammary tissue samples. Tumour tissues $(\mathrm{n}=120)$ and normal background tissues $(n=32)$ of the breast were collected immediately after surgery and stored frozen until use. Patients were routinely followed clinically after surgery. The presence of tumour cells in the collected tissues was verified by a consultant pathologist, who examined H\&E stained frozen sections. Patients were routinely followed-up on a regular basis and details stored in a database. The median follow-up period was 120 months.

Tissue processing, RNA extraction and cDNA synthesis. Frozen sections of tissues were cut at a thickness of 5-10- $\mu \mathrm{m}$ using a cryostat and were kept for immunohistochemistry and routine histology. A further 15-20 sections were mixed and homogenised using a hand-held homogeniser, in ice cold RNA extraction solution. The concentration of RNA was determined using a UV spectrophotometer. Reverse transcription was carried using an RT kit with an anchored oligo-dt primer supplied by AbGene, using $1 \mu \mathrm{g}$ total RNA in a 96-well plate. The quality of cDNA was verified using $B$-actin primers. The transcript of interest, including SDF-2, SDF2L1, SDF-4, SDF-5 and GAPDH (house-keeping control), were amplified using conventional PCR and separated on a
$2 \%$ agarose gel, before stained and documented with a UviTech gel Imager (UviTech, Cambridge, UK).

Quantitative analysis of the SDF-2, SDF2-L1,SDF-4 and SDF-5 transcripts. The level of the SDF transcripts from the above-prepared cDNA was determined using a real-time quantitative PCR, based on the Amplifluor ${ }^{\mathrm{TM}}$ technology, modified from a method previously reported $(19,20)$. Briefly, pairs of PCR primers were designed using the Beacon Designer software (version 2, CA, USA), but to one of the primers, an additional sequence, known as the $\mathrm{Z}$ sequence (5'-actgaacctg accgtaca'-3) which is complementary to the universal $\mathrm{Z}$ probe (Intergen Inc., Oxford, UK), was added. The transcript levels of GAPDH, used as a house-keeping control was also quantified and used for normalisation purpose. Primer sequences are given in Table I. The reaction was carried out using the following: Hot-start Q-master mix (AbGene), 10 pmol of specific forward primer, 1 pmol reverse primer which has the $\mathrm{Z}$ sequence, $10 \mathrm{pmol}$ of FAM-tagged probe (Intergen Inc.), and cDNA from approximate $50 \mathrm{ng}$ RNA. The reaction was carried out using IcyclerIQ ${ }^{\mathrm{TM}}$ (Bio-Rad) which is equipped with an optic unit that allows real-time detection of 96 reactions, using the following condition: $94^{\circ} \mathrm{C}$ for $12 \mathrm{~min}, 50$ cycles of $94^{\circ} \mathrm{C}$ for $15 \mathrm{sec}, 55^{\circ} \mathrm{C}$ for $40 \mathrm{sec}$ and $72^{\circ} \mathrm{C}$ for $20 \mathrm{sec}$. The levels of the transcripts were generated from a standard that was simultaneously amplified with the samples.

Immunohistochemical analysis of SDF proteins. This was based on the method we previously described (21). Frozen sections of mammary tissues were cut at a thickness of $6-\mu \mathrm{m}$ using a cryostat. The sections were mounted on super frost plus microscope slides, air dried and then fixed in a mixture of $50 \%$ acetone and $50 \%$ methanol. The sections were then placed in 'Optimax' wash buffer for 5-10 min to rehydrate. Sections were incubated for $20 \mathrm{~min}$ in a horse serum blocking solution and probed with the primary antibody (1:100 dilution) for $1 \mathrm{~h}$ at room temperature. Following extensive washings, sections were incubated for $30 \mathrm{~min}$ in the secondary biotinylated antibody (Multilink Swine anti-goat/mouse/rabbit immunoglobulin, Dako Inc.). Following washings, Avidin Biotin Complex (Vector Laboratories) was then applied to the sections followed by extensive washings. Diaminobenzidine chromogen (Vector Labs) was then added to the sections which were incubated in the dark for $5 \mathrm{~min}$. Sections were then counter stained in Gill's Haematoxylin and dehydrated in ascending grades of methanol before clearing in xylene and mounting under a cover slip.

Statistical analysis was carried out using Mann-Whitney $\mathrm{U}$ test and the Kruskal-Wallis test. Correlation was carried out using Spearman's rank test on SigmaPlot (version 11).

\section{Results}

Distribution of SDF-2 and SDF-4 in mammary tissues. Normal mammary tissues displayed a good level of SDF-2, in both epithelial cells and in particular in stromal cells in the gland (Fig. 1A). The staining of SDF-2 protein tends to be cytoplasmic. In contrast, in breast cancer tissues, there was a marked reduction in the staining in both tumour cells and 
Table I. Primer sequences.

\begin{tabular}{lll}
\hline Molecule & Sense primer (5'-3') & Anti-sense primer (5'-3') \\
\hline SDF-2 & ggtgaagctactcaatacgc & actgaacctgaccgtacagtaactgttgctgtcatcca \\
SDF2-like-1 & cttacgggcaagaacttg & actgaacctgaccgtacagcactgtccataggtcca \\
SDF-4 & aagctgatggtcatctttc & actgaacctgaccgtacacgtcttctccatgatcca \\
SDF-5 & tttttattttgcaggcttc & actgaacctgaccgtacagacaacgacctttgcatc \\
SDF-1 & ttcaggagtacctggagaaa & actgaacctgaccgtacacctaacactggtttcagagc \\
GAPDH (for Q-PCR) & aaggtcatccatgacaactt & actgaacctgaccgtacagccatccacagtcttctg \\
GAPDH (for conventional RT-PCR) & ggctgctttaactctggta & gactgtggtcatgagtcctt \\
\hline
\end{tabular}
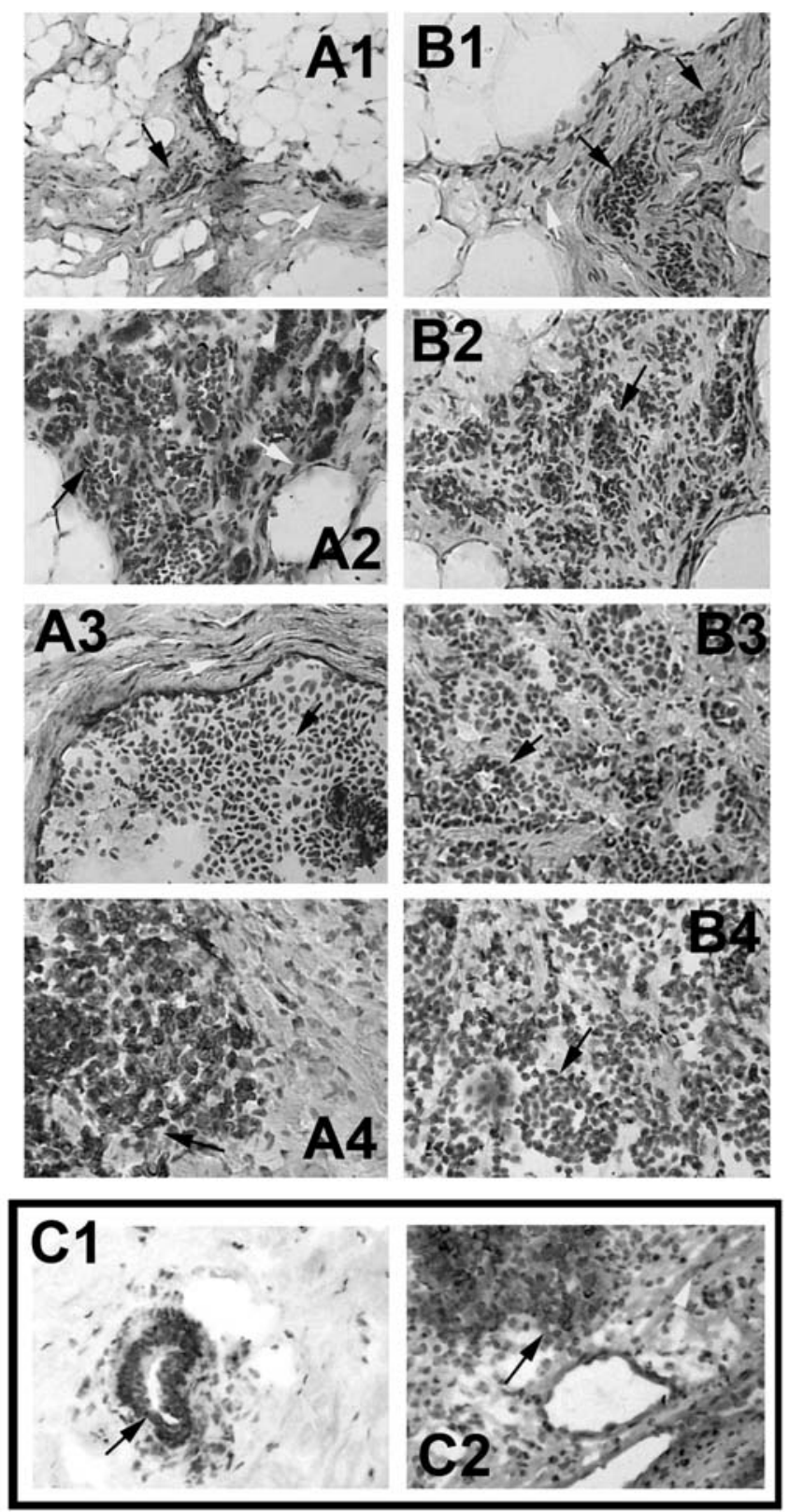

Figure 1. Immunohistochemical staining of SDF-2 (A1-A4), SDF-4 (B1-B4) and SDF-1 (C1 and $\mathrm{C} 2$ ) in normal and tumour tissues. SDF-2 stained strongly in mammary epithelial cells (A1/A2 black arrows), but weakly in breast cancer cells (A3/A4 black arrows). Stromal cells (white arrows) showed similar pattern of staining. Similarly, SDF-4 staining, although weak, are also seen in mammary epithelial cells (B1/B2), but virtually absent in cancer cells (B3/B4). The pattern of staining of both SDF2 and SDF-4 are in contrast to SDF-1 staining $(\mathrm{C} 1$ and $\mathrm{C} 2)$ in which cancer cells show a stronger staining (C2 black arrows) than epithelial cells (C1 black arrow).

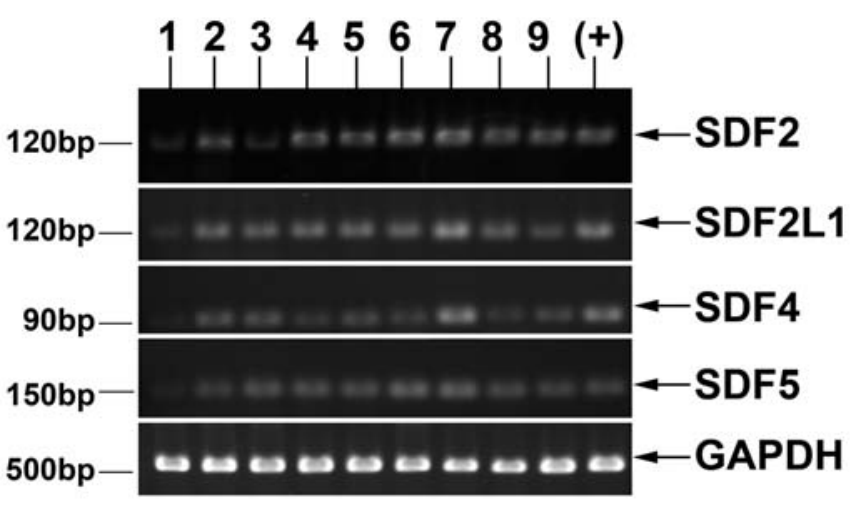

Figure 2. Detection of SDF transcripts in human cell lines. MCF-7 (1), ZR-75-1 (2), MDAMB-436 (3), MDA-MB-231 (4), BT474 (5), BT482 (6), and BT549 (7) are human breast cancer lines, MRC5 (8) and HECV (9) human fibroblast cell line and endothelial cell line, respectively. (+) positive control is cDNA from human mammary tissues.

stromal cells. Cancer cells were frequently seen lacking staining (Fig. 1A3/A4).

The staining of SDF-4 in mammary tissues tends to be weak, compared with that of SDF-2 staining. In normal tissues, the SDF-4 staining appears to be more prominent in epithelial cells than in stromal cells (Fig. 1B1/B2). There is decreased staining in both cancer cells and stromal cells (Fig. 1B3/B4).

The pattern of staining of both SDF-2 and SDF-4 are thus in clear contrast to that of SDF-1, which showed a markedly increased staining in cancer cells compared to normal epithelial cells (Fig. 1C) and as we previously reported (8).

Expression of SDF transcripts in human breast cancer cell lines. Fig. 2 shows the pattern of expressions of SDF-2, SDF2-like-1, SDF-4 and SDF-5 in a panel of breast cancer cell lines, a fibroblast cell line and an endothelial cell line. It is evident that the transcript expression of the SDFs are rather ubiquitous, with most cells having detectable SDF-2, SDF-2L, SDF-4 and SDF-5 transcripts.

SDF-2 and SDF2-like-1 transcripts show reduced expression in tumours from patients with aggressive disease. The most significant observation with the SDF-2 transcript levels was their correlation with the clinical outcome (Fig. 3A). They were significantly lower in patients who developed metastatic disease $(0.0014 \pm 0.0001)$ and patients who died of 

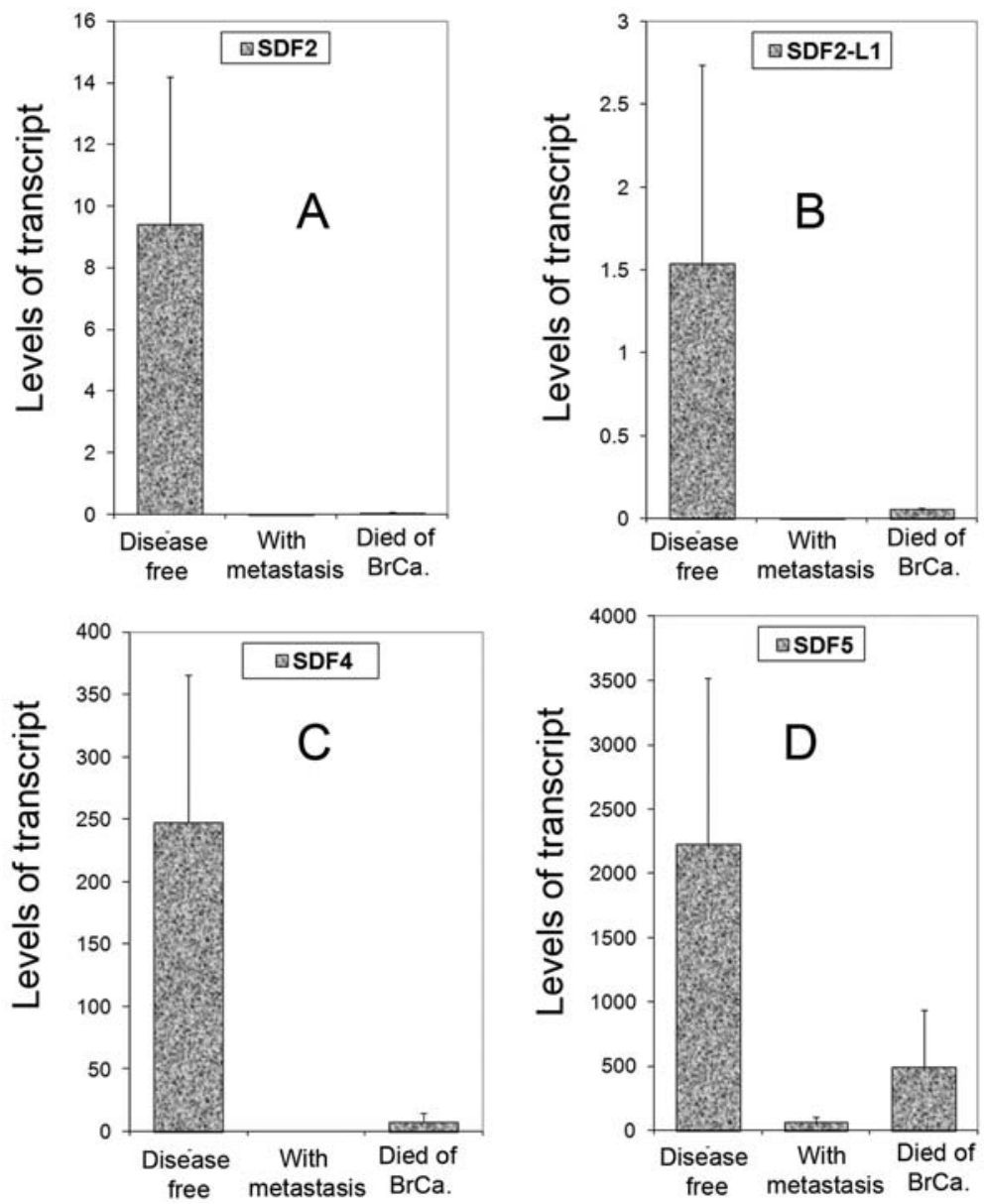

Figure 3. Levels of SDF-2 (A), SDF2-L1 (B), SDF-4 (C) and SDF-5 (D) transcripts in correlation with clinical outcome.
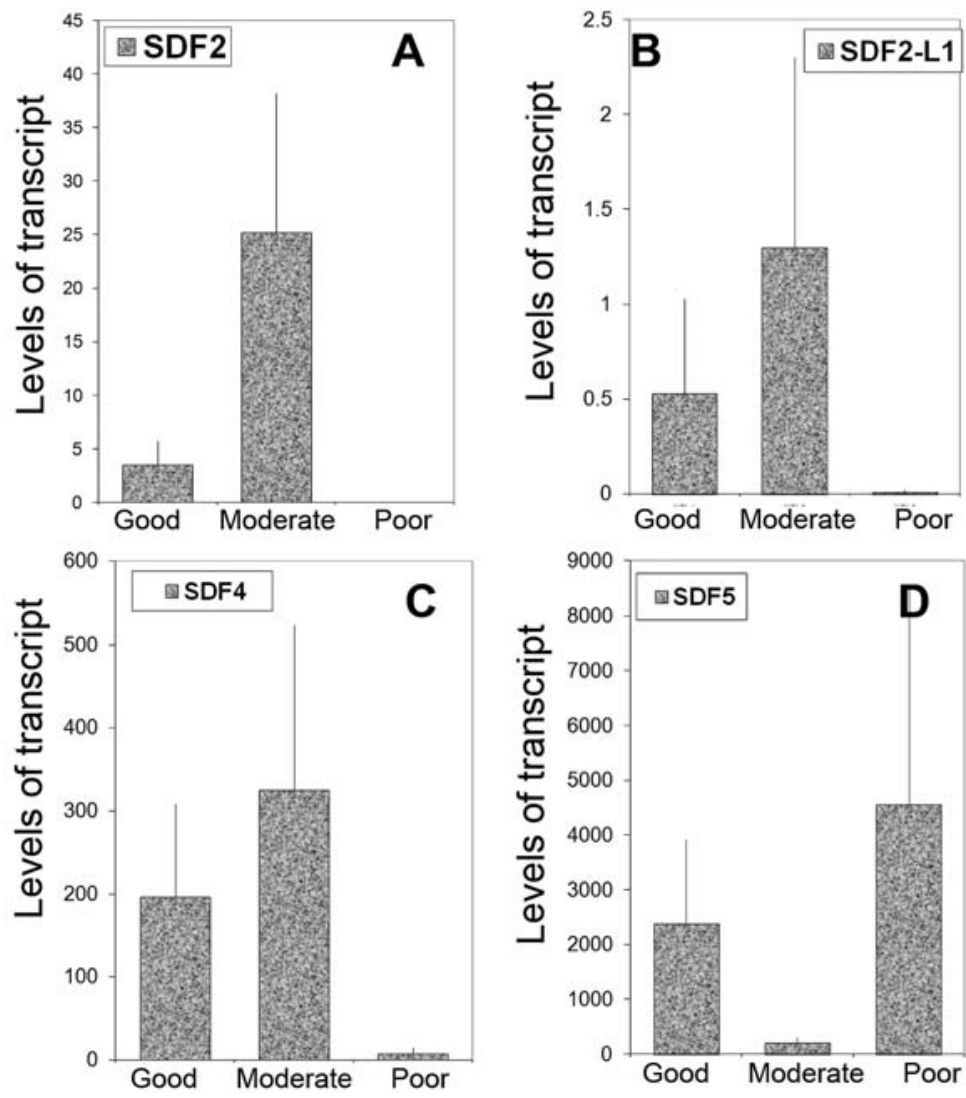

Figure 4. Levels of SDF-2 (A), SDF2-L1 (B), SDF-4 (C) and SDF-5 (D) transcripts in correlation with the Nottingham prognostic index (good - index, <3.4; moderate, 3.4-5.4; poor, >5.4). 

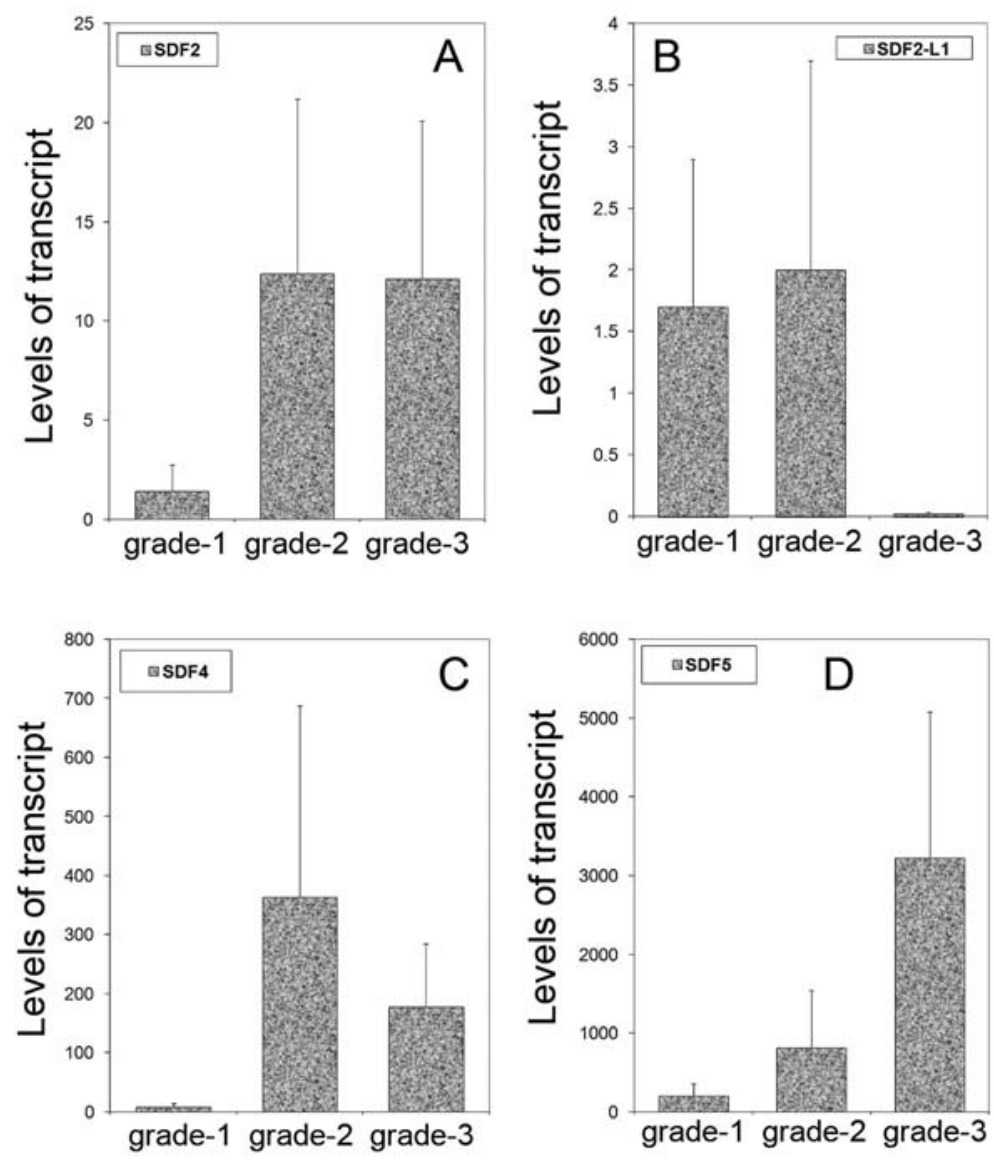

Figure 5. Levels of SDF-2 (A), SDF2-L1 (B), SDF-4 (C) and SDF-5 (D) transcripts in correlation with tumour grade.

breast cancer-related disease $(0.049 \pm 0.037)$ compared with the patients who are disease-free $(9.4 \pm 4.8), \mathrm{p}<0.05$ and $\mathrm{p}=0.05$, respectively. Using the Nottingham Prognostic Index as the prognostic factor, no consistent pattern was observed, except that patients with poor predicted prognosis had low levels of the transcript (Fig. 4A). There was otherwise no significant correlation with tumour grade (Fig. 5A).

Similarly, tumours from poor predicted prognosis showed dramatic low levels of the SDF2-L1 transcript compared with NPI-1 tumours $(0.012 \pm 0.008$ in poor prognosis vs. $0.529 \pm 0.50$ in good prognosis group) (Fig. 4B). Furthermore, grade-3 tumours also displayed low levels of SDF2-L1 compared to grade- 1 and grade- 2 tumours $(0.13 \pm 0.1$ vs. $1.7 \pm 1.4$ and 2.06 \pm 2.0 ) (Fig. 5B). Perhaps the most striking observation for SDF2 L1 was that tumours from patients who developed metastasis $(0.0001 \pm 0.000014)$ and from those who died of breast cancer during the follow-up period $(0.061 \pm 0.051)$ had markedly lower levels compared with tumours from patients who remained disease-free (1.54 \pm 1.20$)$ (Fig. 3B). Finally, ER-positive tumours $(0.15 \pm 0.12)$ had low levels of SDF2-L1 compared with ER-negative tumours (1.7 \pm 1.4$)$. Multivariate analysis revealed that SDF-2 is an independent prognostic indicator for overall survival $(\mathrm{p}=0.047)$ and that SDF2-L1 is an independent prognostic factor for disease-free survival $(\mathrm{p}=0.012)$.

Expression of SDF-4 transcript. Patients who died of breast

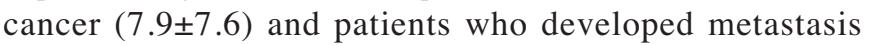

(0.01 \pm 0.01$)$, had significantly lower levels of the SDF-4 transcripts compared with those who remained disease-free $(248 \pm 118), p<0.01$ and $p<0.05$ vs. disease-free group, respectively (Fig. 3C). No significant correlation was seen between SDF-4 transcript and prognostic indices and tumour grade (Figs. 4C and 5C). It is interesting to note that ER-positive tumours had a significantly lower levels of SDF-4 $(34 \pm 23)$ than ER-negative tumours $(328 \pm 143), \mathrm{p}=0.045$.

SDF-5 transcripts are reduced in aggressive tumours. SDF-5 expression showed a similar pattern to that of SDF2-L1. It is noteworthy that patients who were disease-free $(2230 \pm 1290)$ had markedly high levels of SDF5 transcript compared with those with metastatic diseases $(62.7 \pm 41.6)$ and those who died of breast cancer $(495 \pm 446)$ (Fig. 3D). No significant correlation between SDF-5 and prognostic indices was seen, despite the stepwise increase of the transcript with tumour grade. The latter was nonetheless not statistically significant. Finally, using Spearman's rank correlation analysis, we failed to identify a significant correlation between these SDF-2, SDF2-L1, SDF-4, SDF-5 and SDF-1.

\section{Discussion}

In the present study, we report that the expression pattern of SDF-2, SDF2-like-1, SDF-4 and SDF-5 are sharply different from that of SDF-1, in human breast cancer. SDF-2, SDF2-L1 and SDF-4 showed an inverse correlation with the outcome 
of the patients, in a sharp contrast to SDF-1, increased levels of which has been reported to be linked to a poor prognosis (8).

The present study has two significant observations. First, SDF-2/SDF2-like-1 and SDF-4 are potential prognostic indicators for patients with breast cancer. Second, the contrast in expression pattern of SDF-1 and other SDFs, namely, SDF-2L1, SDF-2 and SDF-4. There have been some extensive reports in the literature to show that SDF-1 is over-expressed in breast cancer and that an over-expression of SDF-1 is linked to aggressiveness of the disease. We have shown that SDF-1 is linked to the long-term survival of the patients with breast cancer $(8,9)$. In the present study and using the same cohort for which we investigated expression of SDF-1, we now have first line evidence to show that other SDFs, SDF-2, SDF2-L1, SDF-4, and SDF-5 have a complete different expression from that of SDF-1, and that patients with aggressive tumours have low levels of SDF-2, SDF2-L1 and SDF-4, a striking pattern in comparison with SDF-1.

SDFs are broadly defined and are largely referring to those molecules secreted by stromal cells, with little correlation to their function and structure. In all the SDFs, SDF-1 and SDF-4 belong to the chemokine superfamily, whereas SDF-5 belongs to the secreted frizzled proteins. These genes are coded in different products. Thus, the expression pattern of these SDFs do not necessarily have a natural connection. This is indeed reflected by the present study, in which contrast in pattern of expression was seen between SDF-1 and SDF-2/4/5. SDF-5 was initially discovered from a cDNA library and was to be similar to secreted frizzled-like protein-2 (SFRP-2) or secreted apoptosis-related protein 1 (SARP-1), which forms part of the frizzled transmembrane protein family (13). These proteins are receptors for Wnt family members. The function of SDF-5 is not clear, although it has been suggested that when over-expressed in breast cancer cells it regulates apoptosis of the cells, possibly by way of $\beta-$ catenin $(22,23)$. Little is available with regard to the expression of these new SDFs in cancer. The results on SDF-2 in the present study is in line with another study (18), which indicated that a reduction of SDF-2 in colorectal cancer may be linked to a poor prognosis. Expression pattern between SDF-2 and SDF2-L1 is similar to that in the present study, which may suggest that the two variants likely share a similar function(s) on breast cancer cells. This is interesting, as the two variants were initially discovered from different cell types, i.e., SDF-2 from murine stromal cells and SDF-2L1 from murine hepatocellular carcinoma cells although they share $64 \%$ similarities in their amino acid sequences $(11,14)$. SDF2L1 also share similarities with POMT1 and POMT2 (Protein O-Mannosyltransferase), molecules linked to the Walker-Warburg syndrome (24).

The clear contrast of the expression between SDF-1, and SDF-2/SDF2-L1/SDF-4/SDF-5, argues for a completely different role of these factors in the development and progression of breast cancer. The role of SDF-1 and its specific receptor, CXCR4 in breast cancer is well established. Both SDF-1 and its receptor are associated with a poor clinical outcome. This is clearly supported by the well understood function of the cytokine-receptor complex. As already discussed, these 'stromal' derived factors have little in common in their structure.
It is clear from the immunohistochemical analysis of tissues and PCR on cell lines that the 4 new SDFs are ubiquitously expressed. This observation was made in the initial study by Fukuda et al (14), on SDF2-L1. SDF-5 was initially shown to be expressed at higher levels in muscle tissues (13). It seems though that SDF-2, SDF-4 and SDF-5 share the same pattern of expression in the scenario of breast cancer.

In conclusion, the present study has shown for the first time that SDF-2, SDF-4 and SDF-5, members of the stromal derived factors, have a sharply different pattern of expression from that of SDF-1. While SDF-1, as we previously reported, showed over-expression in aggressive tumours and high levels of SDF-1 is linked to a poor prognosis, SDF-2 and SDF-4 showed a distinct pattern, in which low levels of SDF-2 and SDF-4 are linked to a poor clinical outcome of the patients. This study thus reveals that SDF-2/SDF-4 may act in a different manner in comparison with SDF-1. This warrants further investigation as to the potential therapeutic role of SDF-2 and SDF-4 in breast cancer.

\section{Acknowledgements}

The authors would like to thank Cancer Research Wales, and The Fong Family Foundation for supporting this work.

\section{References}

1. Nagasawa T, Kikutani $\mathrm{H}$ and Kishimoto T: Molecular cloning and structure of a pre-B-cell growth-stimulating factor. Proc Natl Acad Sci USA 91: 2305-2309, 1994.

2. Shirozu M, Nakano T, Inazawa J, Tashiro K, Tada H, Shinohara T and Honjo T: Structure and chromosomal localization of the human stromal cell-derived factor 1 (SDF1) gene. Genomics 28: 495-500, 1995.

3. Salcedo R, Wasserman K, Young HA, Grimm MC, Howard OM, Anver MR, Kleinman HK, Murphy WJ and Oppenheim JJ: Vascular endothelial growth factor and basic fibroblast growth factor induce expression of CXCR4 on human endothelial cells: in vivo neovascularization induced by stromal derived factor- $1 \alpha$. Am J Pathol 154: 1125-1135, 1999.

4. Bartolome RA, Galvez BG, Longo N, Baleux F, van Muijen GN, Sanchez-Mateos P, Arroyo AG and Teixido J: Stromal cellderived factor-1 promotes melanoma cell invasion across basement membranes involving stimulation of membrane-type 1 matrix metalloproteinase and Rho GTPase activities. Cancer Res 64: 2534-2543, 2004.

5. Hall JM and Korach KS: Stromal cell-derived factor 1, a novel target of estrogen receptor action, mediates the mitogenic effects of estradiol in ovarian and breast cancer cells. Mol Endocrinol 17: 792-803, 2003.

6. Zeelenberg IS, Ruuls-van Stalle L and Roos E: The chemokine receptor CXCR4 is required for outgrowth of colon carcinoma micrometastases. Cancer Res 63: 3833-3839, 2003.

7. Muller A, Homey B, Soto H, Ge N, Catron D, Buchanan ME, McClanahan T, Murphy E, Yuan W, Wagner SN, et al: Involvement of chemokine receptors in breast cancer metastasis. Nature 410: 50-56, 2001

8. Kang H, Parr C, Mansel RE and Jiang WG: Stroma-derived factor 1 (SDF-1) and the invasiveness of breast cancer cells, the clinical implications. Breast Cancer Res 7: R402-R410, 2005.

9. Kang W, Watkins G, Douglas-Jones A, Mansel RE and Jiang WG: The elevated level of CXCR4 expression is correlated with lymph node metastasis in human breast cancer. Breast 14: 360-367, 2005.

10. Kang H, Mansel RE and Jiang WG: The role of stroma-derived factor 1 (SDF-1) in the migration and invasion of breast cancer cells. Int J Oncol 26: 1429-1434, 2005.

11. Hamada $\mathrm{T}$, Tashiro K, Tada $\mathrm{H}$, Inazawa $\mathrm{J}$, Shirozu M, Shibahara K, NakamuraT, Martina N, Nakano T and Honjo T: Isolation and characterization of a novel secretory protein, stromal cell-derived factor-2 (SDF-2) using the signal sequence trap method. Gene 176: 211-214, 1996. 
12. Lam PP, Hyvarinen K, Kauppi M, Cosen-Binker L, Laitinen S, Keranen S, Gaisano HY and Olkkonen VM: A cytosolic splice variant of Cab45 interacts with Munc18b and impacts on amylase secretion by pancreatic acini. Mol Biol Cell 18: 2473-2480, 2007.

13. Shirozu M, Tada H, Tashiro K, Nakamura T, Lopez ND, Nazarea M, Hamada T, Sato T, Nakano T and Honjo T: Characterization of novel secreted and membrane proteins isolated by the signal sequence trap method. Genomics 37: 273-280, 1996.

14. Fukuda S, Sumii M, Masuda Y, Takahashi M, Koike N, Teishima J, Yasumoto $\mathrm{H}$, Itamoto $\mathrm{T}$, Asahara $\mathrm{T}$, Dohi $\mathrm{K}$ and Kamiya K: Murine and human SDF2L1 is an endoplasmic reticulum stress-inducible gene and encodes a new member of the Pmt/rt protein family. Biochem Biophys Res Commun 280: 407-414, 2001

15. Scherer PE, Lederkremer GZ, Williams S, Fogliano M, Baldini G and Lodish HF: Cab45, a novel $\left(\mathrm{Ca}^{2+}\right)$-binding protein localized to the Golgi lumen. J Cell Biol 133: 257-268, 1996.

16. Koivu T, Laitinen S, Riento K and Olkkonen VM: Sequence of a human cDNA encoding $\mathrm{Cab} 45$, a $\mathrm{Ca}^{2+}$-binding protein with six EF-hand motifs. DNA Seq 7: 217-220, 1997.

17. Grønborg M, Kristiansen TZ, Iwahori A, Chang R, Reddy R, Sato N, Molina H, Jensen ON, Hruban RH, Goggins MG Maitra A and Pandey A: Biomarker discovery from pancreatic cancer secretome using a differential proteomic approach. Mol Cell Proteomics 5: 157-171, 2006.

18. Vendrell E, Ribas M, Valls J, Solé X, Grau M, Moreno V, Capellà $\mathrm{G}$ and Peinado MA: Genomic and transcriptomic prognostic factors in R0 Dukes B and C colorectal cancer patients. Int J Oncol 30: 1099-1107, 2007.
19. Nazarenko IA, Bhatnagar SK and Hohman RJ: A closed tube format for amplification and detection of DNA based on energy transfer. Nucleic Acids Res 25: 2516-2521, 1997.

20. Jiang WG, Watkins G, Douglas-Jones A, Mokbel K, Mansel RE and Fodstad O: Expression of Com-1/p8 in human breast cancer, and its relevance to clinical outcome and ER status. Int J Cancer 117: 730-737, 2005

21. Jiang WG, Watkins G, Lane J, Douglas-Jones A, Cunnick GH, Mokbel M and Mansel RE: Prognostic value of Rho family and and rho-GDIs in breast cancer. Clin Cancer Res 9: 6432-6440, 2003.

22. Chang JT, Esumi N, Moore K, Li Y, Zhang S, Chew C, Goodman B, Rattner A, Moody S, Stetten G, Campochiaro PA and Zack DJ: Cloning and characterization of a secreted frizzled-related protein that is expressed by the retinal pigment epithelium. Hum Mol Genet 8: 575-583, 1999.

23. Rattner A, Hsieh JC, Smallwood PM, Gilbert DJ, Copeland NG, Jenkins NA and Nathans J: A family of secreted proteins contains homology to the cysteine-rich ligand-binding domain of frizzled receptors. Proc Natl Acad Sci USA 94: 2859-2863, 1997.

24. Jurado LAP, Coloma A and Cruces J: Identification of a human homolog of the Drosophila rotated abdomen gene (POMT1) encoding a putative protein $\mathrm{O}$-mannosyltransferase, and assignment to human chromosome 9q34.1. Genomics 58: 171-180, 1999 